\title{
THE GLOBAL GOALS FOR SUSTAINABLE DEVELOPMENT
}

SNAPSHOTS FROM MALTA

THE PRESIDENT'S FOUNDATION FOR THE WELLBEING OF SOCIETY

SAN ANTON PALACE 2016 


\section{THE GLOBAL GOALS}

Snapshots from Malta

\section{THEGLOBAL GOALS}

For Sustainable Development
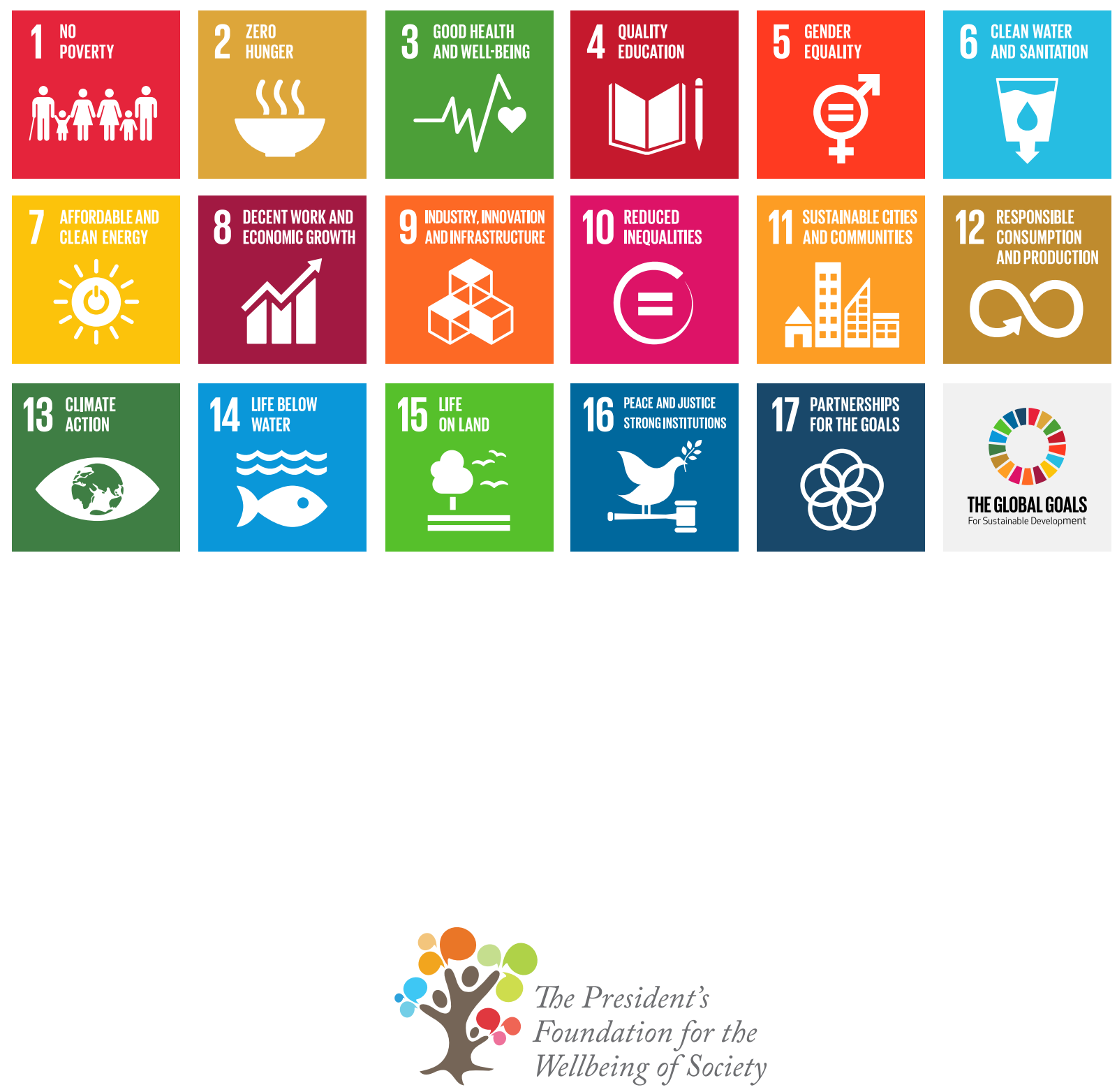
This report was initiated by the National Observatory for Living with Dignity, within the President's Foundation for the Wellbeing of Society.

Chairperson: $\quad$ Professor Carmel Borg

Members: $\quad$ Dr Katrine Camilleri

Dr Vincent Caruana

Dr Marceline Naudi

Dr Mary Grace Vella

Edited by: $\quad$ Dr Sharon Attard

This is a peer-reviewed publication.

The views expressed within this publication are solely those of the authors, and do not necessarily reflect the position of the President of Malta, or the President's Foundation for the Wellbeing of Society. The pictures reproduced within this publication were selected by the contributors to this volume, each of whom took individual responsibility for securing the necessary permissions for the pictures to be reproduced.

The texts and pictures for this publication were adapted from presentations on the United Nations Sustainable Development Goals, delivered in April 2016, and Powered by PechaKucha. The presentations formed part of a Workshop initiated by the National Observatory for Living with Dignity, within the President's Foundation for the Wellbeing of Society.

ISBN: 978-99957-881-6-2

(C) The President's Foundation for the Wellbeing of Society, 2016 San Anton Palace, Attard, Malta 


\section{Table of Contents}

Foreword from Her Excellency, The President of Malta..................................................

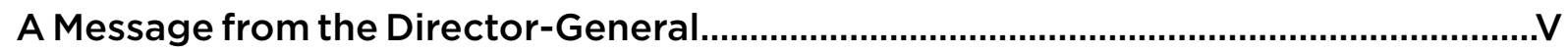

An Introduction from the Chair................................................................................

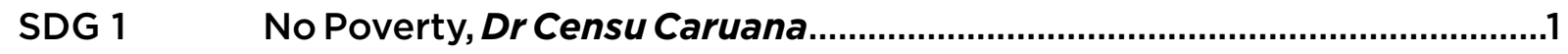

SDG 2 Zero Hunger, Prof Suzanne Piscopo.....................................................4

SDG 3 Good Health and Wellbeing, Dr Ruth Farrugia......................................10

SDG 4 Quality Education, Prof Carmel Borg....................................................16

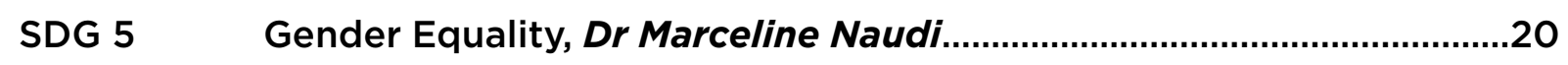

SDG 6 Clean Water and Sanitation, Mr Julian Mamo.......................................26

SDG 7 Affordable and Clean Energy, Eur Ing Dr Charles Yousif.......................30

SDG 8 Decent Work and Economic Growth, Dr Gordon Cordina \& Dr Sue Vella...34

SDG 9 Industry, Innovation and Infrastructure, Prof Godfrey Baldacchino......40

SDG $10 \quad$ Reduced Inequalities, Dr Katrine Camilleri...........................................44

SDG 11 Sustainable Cities and Communities, Perit Amber Wismayer...............50

SDG 12 Responsible Consumption and Production, Prof Paul Pace.............54

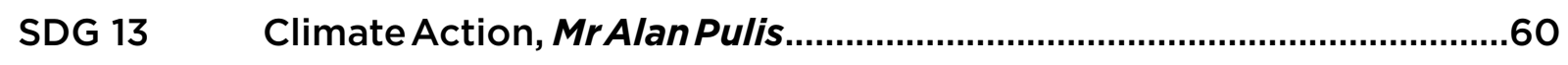

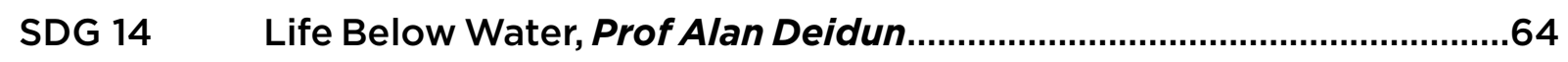

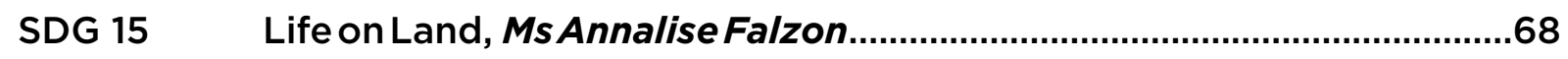

SDG 16 Peace, Justice, and Strong Institutions, Dr Mary Grace Vella................72

SDG 17 Partnership for the Goals, Dr Marie Briguglio........................................78 


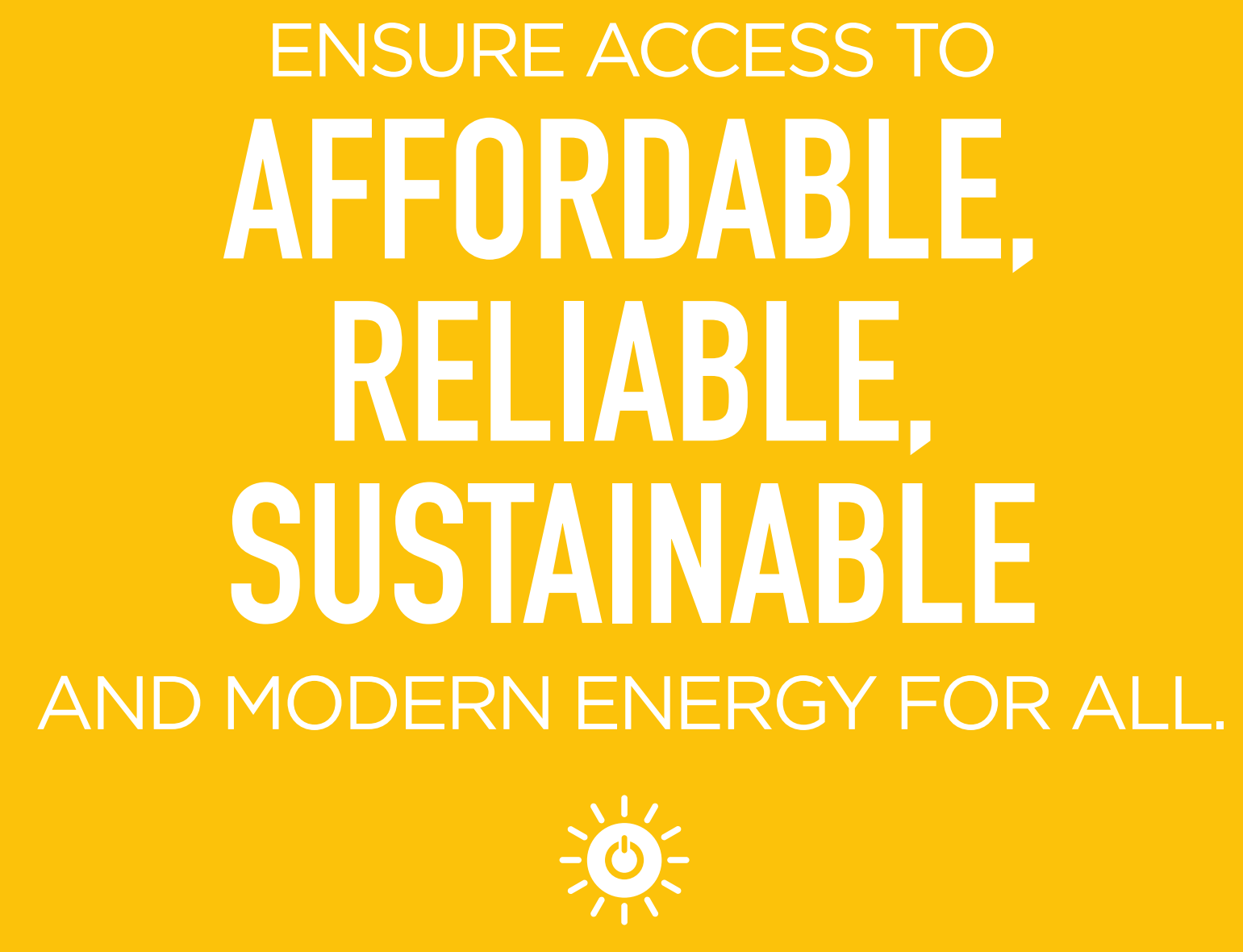

\section{SDG 7 - AFFORDABLE \& CLEAN ENERGY EUR ING DR CHARLES YOUSIF}

THE GLOBAL GOALS For Sustainable Development 7 AFFORDABLEAND
GLEAN ENERGY $\left.\int^{1} \int^{1}\right)^{2}$ 
Where is Malta today, in terms of Sustainable Energy? The electricity interconnector coupled with the BWSC extension of the power station has helped to reduce Malta's carbon dioxide emissions by $27 \%$. At the same time, Malta's economy has improved over the years. However, energy consumption at the demand side (i.e. the user) has not decreased in the way that it should have. Energy intensity is a measure of energy efficiency in economy, and this is currently quite stable. There is need for this to go down, and go down consistently. Our renewable energy generation from solar photovoltaic systems and solar heaters (as well as other sources) is increasing. However, the renewable energy being produced is also being consumed. When this is added to the total electricity production in Malta, the overall amount is still quite stable.

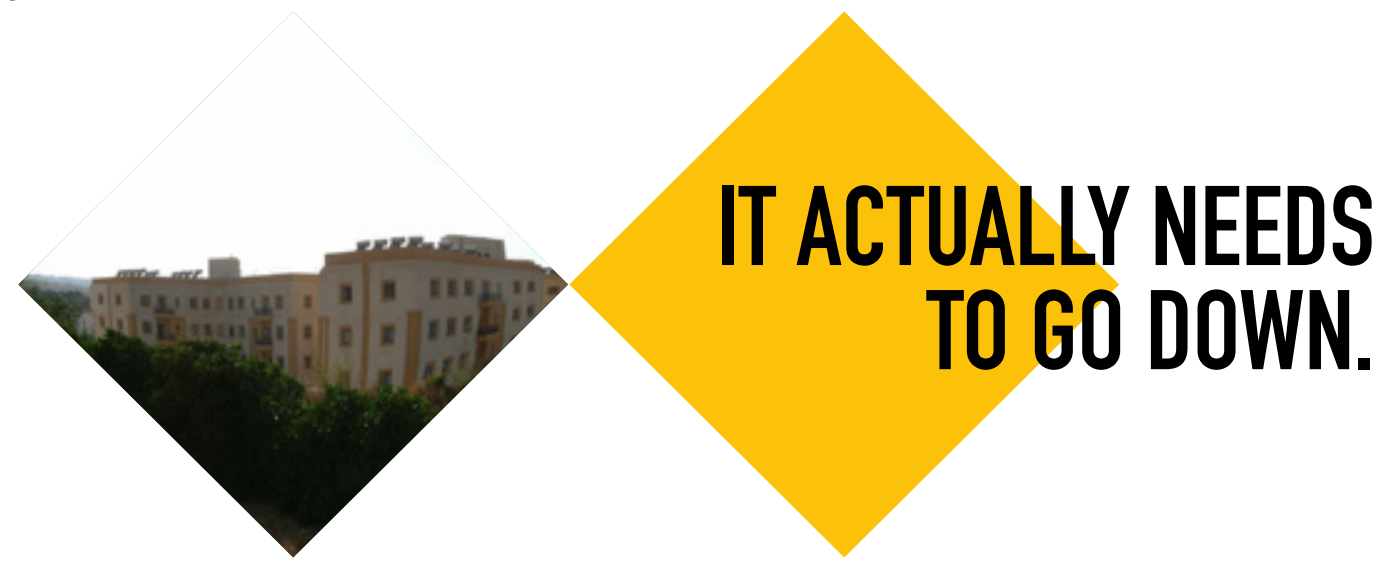

There are many things which individuals can do to make a contribution to this goal. Each person should ask themselves: When was the last time that I implemented an energy efficiency measure at home? Have I done anything, since changing the bulbs to energy efficient ones, to contribute towards sustainable energy? Many homes often use ghost loads - the sleeping energy consumption of stand-by equipment. People do not need to have so many clocks and sets running in their home for 24 hours a day.
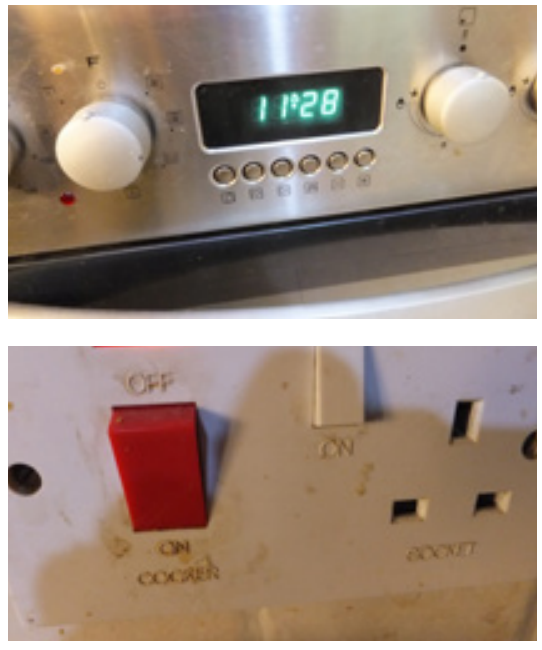
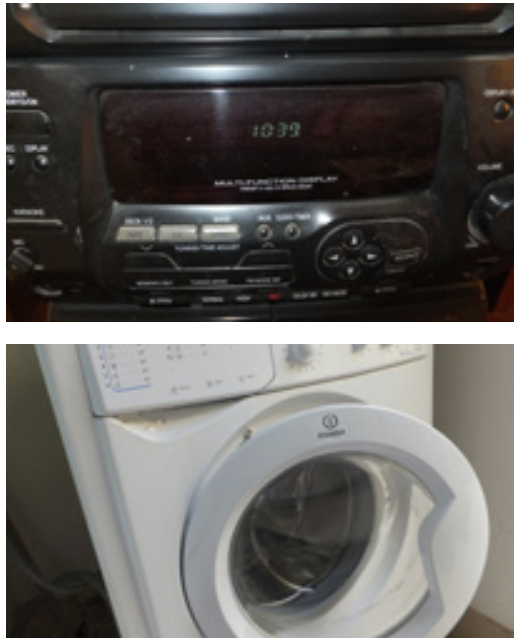

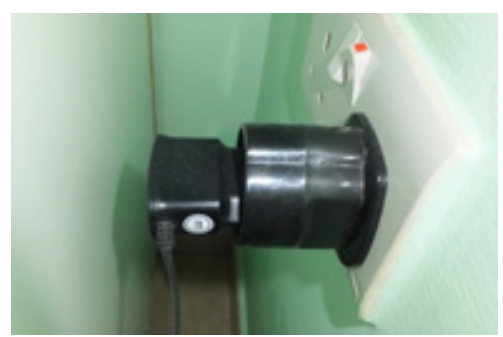

THESE CAN AFFORD TO BE SWITCHED OFF, ESPECIALLY AT NIGHIT.

PHOTO CREDIT

EUR ING CHARLES YOUSIF 
When buying new white goods, people should be mindful of the fact that larger washing machines often consume more electrical energy and water (despite being rated higher than a smaller machine). In terms of heating, it's interesting to note that over $80 \%$ of Maltese homes still use an electric boiler for water heating. More energy is lost when the electric boiler is left switched on. The water remains hot, and the heat is lost to the surrounding air. Today, there are other options for how to heat water. A heat pump water heater consumes only $30 \%$ of what an electric boiler does. This should only be switched on once a day, and not left on stand-by.

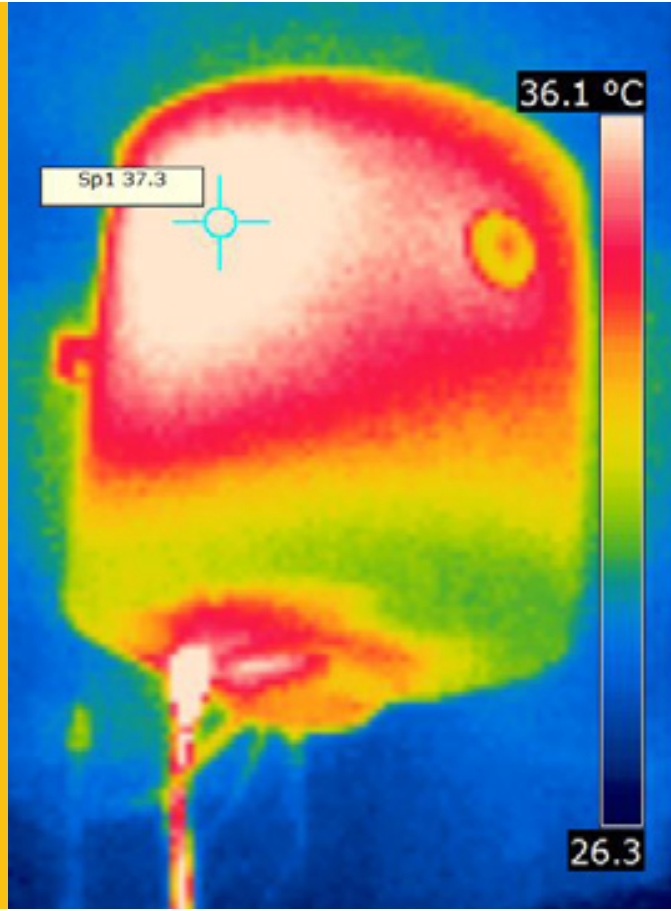

Individuals should look around their homes, to consider the ways that they can make better use of natural light. Desks or dressing tables (whichever is used more) can be moved closer to sources of natural light, so that artificial light is not needed. Our buildings should also be considered. Do windows or roofs occupy the most space? Therefore, does it make sense to insulate the roofs first, or install doubleglazing? How about a single wall overlooking the internal yard, where the heat is unbearable during summer? When it comes to shading, it is quite possible to have clever, beautiful, and simple designs to ensure that the sun does not overheat our homes. Exterior rendering and colours is also crucial. In Malta, does it make sense for walls to be painted dark grey or black? Mediterranean people love colours, and light colours should be used in order to avoid overheating. Homes which are built below the minimum energy standards set by regulations should be boycotted. External walls must be insulated, or at least be of the double wall type.

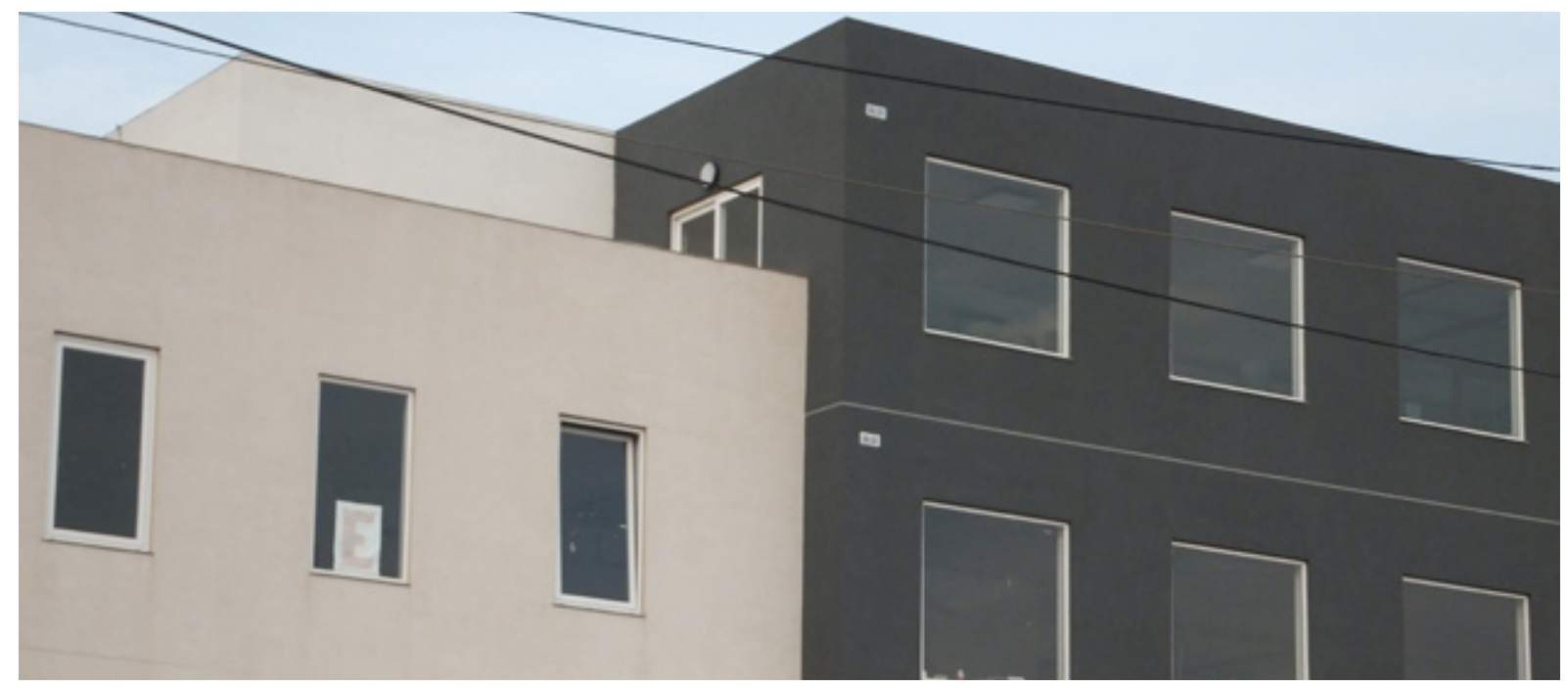




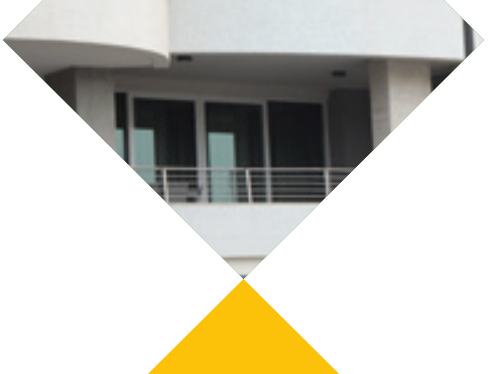

Consider solar energy - should people go for photovoltaics (PV), or solar heating? For the same amount of energy saving, solar heaters occupy half the space of PV panels, cost 50\% less, and are three times more efficient. Moreover, solar water heaters store energy for the night, whilst PV requires purchasing electricity from the grid after sunset. The only large scale solar heating project in Malta was built in 2004, by the Housing Authority in St Julian's. From this point on, the popularity of solar heating dropped.

It is important to look at existing policies, and whether these are always effective. New 2015 regulations dictate that a solar heater and a solar PV panel cannot be placed more than one metre above roof level. This is inhibiting the full potential of solar systems in Malta, and is technically unsound. Facades could easily be used to install PV systems, while providing shading for indoor areas. Creative solutions are needed. The ground can be used to absorb heat in winter, and reject heat in summer. This is already standard practice in the USA, and in parts of Europe.

It's similarly important to be aware of our surrounding environment, and our collective wellbeing. Over $60 \%$ of solar UV radiation can reach our bodies on a clear sunny day, even in the shade. An umbrella no longer provides enough protection from UV radiation. App technology can now assist individuals to monitor safe levels of exposure to UV radiation, allowing for sustainability in caring for ourselves and protecting our bodies from harmful radiation. Both formal and informal education is needed, in order to increase awareness of how energy efficient systems work. It should not be assumed that an energy efficient system will save energy. They must be used correctly, in order to be successful.

The choice belongs to each and every one of us. Just like this child, about to make their choice during the traditional Maltese qućcija on their first birthday.
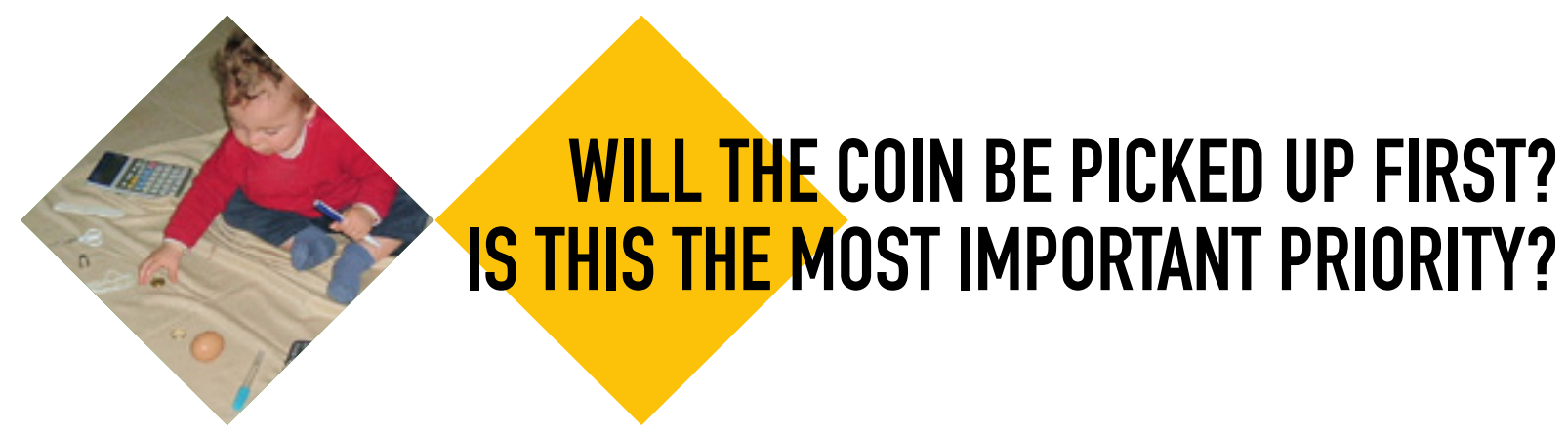

Or will the choice be made to save the world, by undertaking a fair share on sustainable energy? Do we want happy and smiling children living in a healthy world, or will we allow children who are lacking in wellbeing? The choice is ours to make. Let us start with one simple, energy-saving activity today.

\section{References:}

Technical Document Part F: Minimum Energy Performance Requirements for Buildings in Malta Part 1, Building Regulation Office, Ministry for Transport and Infrastructure, 2015. 